\title{
Postprandial glucagon-like peptide-1 secretion is increased during the progression of glucose intolerance and obesity in high-fat/high-sucrose diet-fed rats
}

\author{
Shingo Nakajima ${ }^{1,2}$, Tohru Hira ${ }^{1 *}$ and Hiroshi Hara ${ }^{1}$ \\ ${ }^{1}$ Division of Applied Bioscience, Research Faculty of Agriculture, Hokkaido University, Kita-9, Nishi-9, Kita-ku, \\ Sapporo 060-8589, Japan \\ ${ }^{2}$ Department of Mental Disorder Research, National Institute of Neuroscience, National Center of Neurology and Psychiatry, \\ Tokyo, Japan
}

(Submitted 25 August 2014 - Final revision received 14 December 2014 - Accepted 3 February 2015 - First published online 1 April 2015)

\section{Abstract}

Glucagon-like peptide-1 (GLP-1) is secreted by distal enteroendocrine cells in response to luminal nutrients, and exerts insulinotropic and anorexigenic effects. Although GLP-1 secretory responses under established obese or diabetic conditions have been studied, it has not been investigated whether or how postprandial GLP-1 responses were affected during the progression of diet-induced obesity. In the present study, a meal tolerance test was performed every week in rats fed a high-fat and high-sucrose (HF/HS) diet to evaluate postprandial glycaemic, insulin and GLP-1 responses. In addition, gastric emptying was assessed by the acetaminophen method. After 8 weeks of HF/HS treatment, portal vein and intestinal mucosa were collected to examine GLP-1 production. Postprandial glucose in response to normal meal ingestion was increased in the HF/HS group within 2 weeks, and its elevation gradually returned close to that of the control group until day 50. Slower postprandial gastric emptying was observed in the HF/HS group on days 6, 13 and 34. Postprandial GLP-1 and insulin responses were increased in the HF/HS group at 7 weeks. Higher portal GLP-1 and insulin levels were observed in the HF/HS group, but mucosal gut hormone mRNA levels were unchanged. These results revealed that the postprandial GLP-1 response to meal ingestion is enhanced during the progression of diet-induced glucose intolerance and obesity in rats. The boosted postprandial GLP-1 secretion by chronic HF/HS diet treatment suggests increased sensitivity to luminal nutrients in the gut, and this may slow the establishment of glucose intolerance and obesity.

Key words: Obesity: Glucagon-like peptide-1: High-fat and high-sucrose diet: Meal tolerance test

Obesity and glucose intolerance are major risk factors for various diseases, such as cancer, depression, diabetes and $\mathrm{CVD}^{(1-3)}$. Excessive energy (food) intake is a critical cause of obesity. In response to every meal ingestion, various gut hormones are immediately released from enteroendocrine cells to regulate postprandial responses, including gut motility, pancreatic endocrine and exocrine secretion, and satiety induction $^{(4,5)}$. Since some gut hormones have anorexigenic and insulinotropic action, enteroendocrine hormone mimetics is thought to be a new therapy for obesity and/or diabetes ${ }^{(5,6)}$.

Postprandial glycaemia is tightly regulated not only by insulin action but also by the gastric emptying $\operatorname{rate}^{(7)}$. Glucagon-like peptide-1 (GLP-1) has critical roles in maintaining postprandial glycaemia through its insulinotropic effect and gastric inhibitory effect ${ }^{(8)}$. Secretion of GLP-1 is stimulated by luminal nutrients, including glucose, fatty acids, proteins, protein hydrolysates and amino acids ${ }^{(9,10)}$, indicating that postprandial GLP-1 release represents sensitivity to luminal nutrients in the gut. Because of these physiological functions of GLP-1, incretin-based therapy using GLP-1 receptor agonists or dipeptidyl peptidase-IV inhibitors is increasingly used for the treatment of diabetes ${ }^{(11,12)}$.

Although the insulinotropic effect of GLP-1 under a normal condition and improvement of glucose tolerance under a diabetic condition by GLP-1-based therapies are well recognised, changes (reduced, enhanced or unchanged) in nutrientinduced GLP-1 secretion in type 2 diabetic patients are still controversial $^{(13-15)}$. In a high-fat (HF) diet-induced obesity animal model, GLP-1 secretory response to glucose was decreased $^{(16,17)}$, but the response to fatty acids remained

Abbreviations: CCK, cholecystokinin; GLP-1, glucagon-like peptide-1; HF/HS, high-fat and high-sucrose; HOMA-IR, homeostasis model assessment of insulin resistance; MTT, meal tolerance test.

*Corresponding author: T. Hira, fax +81 11706 2811, email hira@chem.agr.hokudai.ac.jp 
unchanged $^{(18)}$. However, it has not yet been characterised whether the GLP-1 secretory response to 'meal' is decreased or increased during the progression of diet-induced obesity. In the present study, rats were fed with a high-fat and high-sucrose (HF/HS) diet to induce obesity. To examine the physiological response to meal ingestion during the progression of obesity, a 'normal diet' was orally given to rats every week for the measurement of postprandial plasma glucose, insulin and GLP-1 levels using the meal tolerance test (MTT) rather than loading a glucose solution (oral glucose tolerance test).

\section{Materials and methods}

\section{Animals}

Male Sprague-Dawley rats (5 weeks old) were purchased from Japan SLC. The experiments were performed in a temperature-controlled room maintained at $23 \pm 2{ }^{\circ} \mathrm{C}$ with a $12 \mathrm{~h}$ light $-12 \mathrm{~h}$ dark cycle (light period 08.00-20.00 hours). The rats were fed an American Institute of Nutrition (AIN)93G (control) diet for 1 week as an acclimatisation period, and then divided into three groups based on body weight. The control and HF/HS groups were, respectively, fed ad libitum with the AIN-93G diet or a fat/sucrose-rich diet (for the composition of each diet, see Table 1). Generally, intake of a HF/HS diet is lower than the intake of the control diet due to the high energy density of the HF/HS diet, which would result in a relatively lower intake of protein, minerals and vitamins in the HF/HS group compared with the control group, and deficiency in these nutrients could, in turn, affect the expression of nutrient transporters and receptors ${ }^{(19-21)}$. To compensate the effect of lower protein/mineral/vitamin intake in the HF/HS group, a food-restricted group was included in the present study. The rats in the food-restricted group were fed the control diet with the same amount (in g) as that consumed by the HF/HS group on the previous day to examine the effects of reduced intake of nutrients, such as protein, minerals and vitamins. All rats had free access to water throughout the experiment. The study was approved by the Hokkaido University Animal Committee, and the

Table 1. Composition of the experimental diets

\begin{tabular}{lcc}
\hline & Control diet $(\mathrm{g} / \mathrm{kg})$ & HF/HS diet $(\mathrm{g} / \mathrm{kg})$ \\
\hline Maize starch & 397.486 & 0 \\
Casein & 200 & 200 \\
Dextrinised maize starch & 132 & 0 \\
Sucrose & 100 & 399.486 \\
Soyabean oil & 70 & 70 \\
Lard oil & 0 & 230 \\
Fibre† & 50 & 50 \\
Mineral mix (AIN-93G-MX) & 35 & 35 \\
Vitamin mix (AIN-93-VX) & 10 & 10 \\
L-Cystine & 3 & 3 \\
Choline bitartrate & 2.5 & 2.5 \\
tert-Butylhydroquinone & 0.014 & 0.014 \\
Total & 1000 & 1000 \\
\end{tabular}

HF/HS, high-fat and high-sucrose; AIN, American Institute of Nutrition.

* TK-16 (Matsutani Chemical Industry Company Limited).

† JustFibre (Morimura Bros., Inc.). animals were maintained in accordance with the guidelines for care and use of laboratory animals at Hokkaido University.

\section{Experimental protocol for the meal tolerance test}

A MTT was conducted every week to examine postprandial glycaemic and GLP-1 responses after single meal (control diet) ingestion throughout the experiment. The rats were fasted for $6 \mathrm{~h}\left(09.00-15.00\right.$ hours ${ }^{(22-24)}$, and then orally administrated the AIN-93G ( $3 \mathrm{~g} / \mathrm{kg}$ body weight) diet suspended in deionised water $(0.167 \mathrm{~g} / \mathrm{ml}, 18 \mathrm{ml} / \mathrm{kg}$ body weight $)$ by a feeding tube ( $6 \mathrm{Fr}$; Atom Medical Company). The suspension contained acetaminophen $(100 \mathrm{mg} / \mathrm{kg}$ body weight) to evaluate the gastric emptying rate ${ }^{(25,26)}$. Blood samples $(120 \mu \mathrm{l})$ from the tail vein were collected before $(0 \mathrm{~min})$ and at 15 , 30, 60, 90 and $120 \mathrm{~min}$ after the oral meal administration. Blood samples were immediately mixed with aprotinin (final concentration $500 \mathrm{KIU} / \mathrm{ml}$; Wako Pure Chemical Industries Limited) and heparin (final concentration $25 \mathrm{IU} / \mathrm{ml}$; Nacalai Tesque, Inc.) on ice. Plasma was separated from the blood samples by centrifugation at $2300 \mathrm{~g}$ for $10 \mathrm{~min}$ at $4^{\circ} \mathrm{C}$, and then frozen at $-80^{\circ} \mathrm{C}$ until measurements were taken. Plasma glucose and acetaminophen levels were measured using a glucose CII-test kit (Wako) and acetaminophen detection kit (Kanto Chemical Company, Inc.), respectively. Homeostasis model assessment of insulin resistance (HOMAIR) was calculated using the following formula:

$$
\begin{aligned}
\text { HOMA-IR }= & (\text { fasting plasma glucose }(\mathrm{mmol} / \mathrm{l}) \\
& \times \text { fasting plasma insulin }(\mathrm{mIU} / \mathrm{l})) / 135,
\end{aligned}
$$

where $1 \mathrm{mg}$ insulin $=26 \mathrm{IU}$.

\section{Blood and tissue collection at the final day}

After overnight fasting, the rats were anaesthetised using sodium pentobarbital (Somnopentyl; Kyoritsu Seiyaku Company) on day 56. The waist circumference length (mid-line girth) of individual rats was measured as an obesity parameter that reflects the amount of adipose tissue ${ }^{(27,28)}$. Portal blood was collected into a syringe containing heparin (final concentration $25 \mathrm{IU} / \mathrm{ml}$ ), aprotinin (final concentration $540 \mathrm{KIU} / \mathrm{ml}$ ) and dipeptidyl peptidase 4 (DPP-IV) inhibitor (final concentration $50 \mu \mathrm{M}$; Millipore). Mucosal samples were collected from the middle (approximately $10 \mathrm{~cm}$ ) duodenum, jejunum, ileum and colon, respectively, after washing out the luminal content with cold saline. Caecal mucosa was collected from the whole caecal tissue after washing out the caecal content with cold saline. These samples were immediately frozen with liquid $\mathrm{N}_{2}$, and stored at $-80^{\circ} \mathrm{C}$ until RNA extraction.

\section{Plasma hormone measurement}

Plasma GLP-1 concentrations $(25 \mu \mathrm{l})$ were measured with the Total GLP-1 enzyme immunoassay (EIA) Kit (intra- and interassay variations $<5$ and $<12 \%$, respectively; Millipore), according to the manufacturer's instructions. Plasma insulin concentrations $(10 \mu \mathrm{l})$ were measured with an insulin-ELISA 
kit (intra- and inter-assay variations $<5$ and $<5 \%$, respectively; AKRIN-010T; Shibayagi), according to the manufacturer's protocols. Plasma collected on day 50 was diluted two times to adjust for a standard curve. For the measurement of plasma cholecystokinin (CCK) and gastrin levels, plasma was extracted as described in a previous study ${ }^{(29)}$. In brief, one volume of plasma sample was mixed with two volumes of $99.5 \%$ ethanol. The mixture was incubated on ice for $30 \mathrm{~min}$, and then centrifuged at $9300 \mathrm{~g}$ for $10 \mathrm{~min}$ at $4^{\circ} \mathrm{C}$. The supernatant was transferred to a new tube and evaporated in a vacuum centrifuge. The dried extracts were stored at $-80^{\circ} \mathrm{C}$ until analysis. After reconstituting into an equivalent volume by assay buffer, plasma concentrations of CCK $(50 \mu \mathrm{l})$ and gastrin $(100 \mu \mathrm{l})$ were measured according to the manufacturer's protocols.

Because the primary antiserum in the CCK EIA Kit (intra- and inter-assay variations $<5$ and $<14 \%$, respectively; Phoenix Pharmaceuticals, Inc.) cross-reacts (100\%) not only with sulphated and non-sulphated CCK- $8^{(26-33)}$, but also with gastrin-1, we measured plasma gastrin concentration using the human gastrin-1 EIA kit (intra- and inter-assay variations $<9$ and $<7 \%$, respectively; Assay Designs, Inc.). The primary antiserum in the Human Gastrin-1 EIA Kit has high reactivity with rat gastrin-1 (70.7\%), human gastrin-1 (100\%) and human mini gastrin $(74.6 \%)$, but it slightly reacts with CCK-8 (2.67\%).

\section{Real-time quantitative PCR}

Total RNA was extracted by using the RNeasy Mini Kit (Qiagen), according to the manufacturer's protocol. RNA concentrations were determined by optical densitometry at $260 \mathrm{~nm}$. RNA quality was assessed by the ratio of 260/ $280 \mathrm{~nm}(>1 \cdot 8)$. Complementary DNA was synthesised using the ReverTra Ace Quantitative PCR with a genome DNA remover (Toyobo Company Limited), according to the manufacturer's protocol. Gene expression levels were determined by TaqMan gene expression assays (Life Technologies Company) with rat gene-specific, predesigned TaqMan primers and probe sets (proglucagon (Gcg): Rn00562293_m1, Cck: Rn00563215_m1). PCR amplification and fluorescence data collection were performed with the Mx3000P RealTime PCR System (Agilent Technologies, Inc.). The mRNA expression level was calculated with a standard curve determined from several concentrations of complementary DNA. The concentration of samples was corrected with glyceraldehyde 3-phosphate dehydrogenase (Gapdb) (Rn999 99916_s1) mRNA as a reference gene. Data are presented as the relative expression level to that of the control group.

\section{Statistical analysis}

All results are expressed as means with their standard errors. In the MTT, data were analysed by a three-way ANOVA with treatment, time and day as main factors (SPSS Japan). When there were significant main effects or interaction, a two-way ANOVA (treatment and time) was performed to identify the main effects on each day. Data on AUC, HOMA-IR, mRNA expression and portal hormone levels were analysed by a one-way ANOVA (treatment) or two-way ANOVA (treatment and day). Significant differences among the groups or time points were determined by Student's $t$ test, Tukey-Kramer's or Dunnett's post boc test $(P<0 \cdot 05)$. The AUC of plasma glucose, insulin and GLP-1 levels during the MTT was calculated by the trapezoidal rule.

\section{Results}

Effect of the high-fat and high-sucrose diet on body weight, food intake, waist circumference, fat accumulation and liver weight

Body weight was increased in the HF/HS group, with significant differences being observed from day 30 compared with the control group (Fig. 1). At the end of the experiment (day 56) (Table 2), the body weight of the HF/HS group was significantly higher than that of the control and foodrestricted groups. The total food intake of the HF/HS group was significantly lower than that of the control group, while total energy intake was significantly higher in the HF/HS group than in the other two groups. To confirm the effect of micronutrient deficiency caused by the decreased intake of the HF/HS diet, a food-restricted group was included in the experiment. The energy intake of the food-restricted group was significantly lower than that of the control and HF/HS groups, but the weight of total food intake in the restricted group was similar to that in the HF/HS group. This indicates that the total intake of protein, vitamins and minerals did not differ between the food-restricted and HF/HS groups. Similar to the results reported for a $\mathrm{HF} \operatorname{diet}^{(30,31)}$, the chronic intake

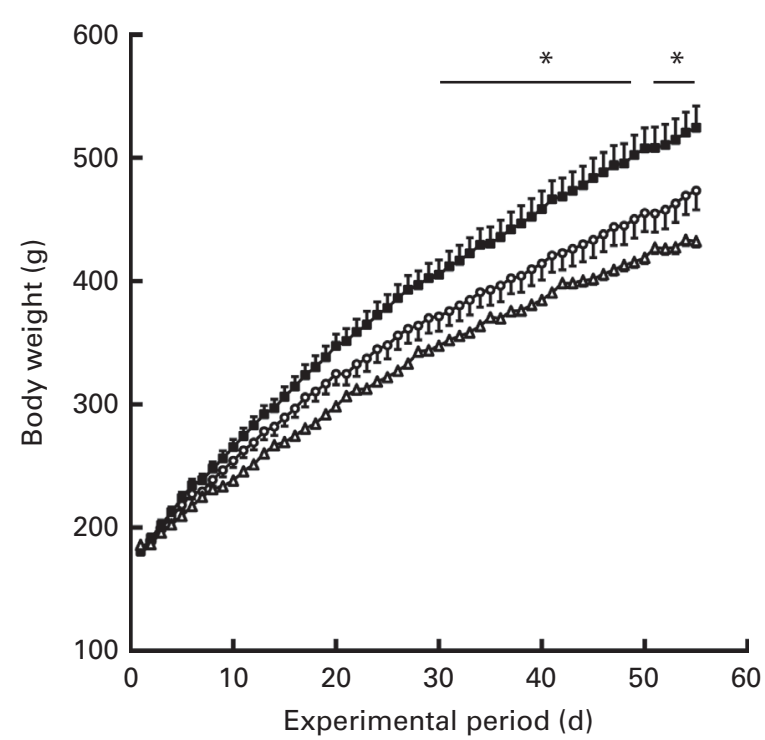

Fig. 1. Daily changes in body weight. Rats were fed the control diet ad libitum $(-0-)$, a restricted amount of the control diet $\left(-\triangle_{-}\right)$and the high-fat and highsucrose diet ad libitum (-), except on the day of the meal tolerance test. Body weight was measured every morning. Values are means $(n 8-9$ rats per group), with their standard errors represented by vertical bars. * Mean value was significantly different from that of the control group $(P<0.05$; TukeyKramer's post hoc test). 
Table 2. Body weight, total food intake, waist, visceral adipose tissue weight and liver weight on day 56 after chronic intake of the high-fat and high-sucrose (HF/HS) diet

(Mean values with their standard errors; $n$ 8-9 rats per group)

\begin{tabular}{|c|c|c|c|c|c|c|}
\hline & \multicolumn{2}{|c|}{ Control group } & \multicolumn{2}{|c|}{$\begin{array}{l}\text { Food-restricted } \\
\text { group }\end{array}$} & \multicolumn{2}{|c|}{ HF/HS group } \\
\hline & Mean & SEM & Mean & SEM & Mean & SEM \\
\hline Initial body weight (g) & 178.5 & 3.6 & $177 \cdot 4$ & $3 \cdot 1$ & 179.9 & $2 \cdot 9$ \\
\hline Final body weight (g) & $453 \cdot 7^{b}$ & $14 \cdot 8$ & $424 \cdot 0^{\mathrm{b}}$ & 4.6 & $508 \cdot 3^{\mathrm{a}}$ & $16 \cdot 8$ \\
\hline Total food intake (g) & $1161^{\mathrm{a}}$ & 32 & $1030^{\mathrm{b}}$ & 1 & $1002^{b}$ & 34 \\
\hline \multicolumn{7}{|l|}{ Total energy intake } \\
\hline $\mathrm{kJ}$ & $19196^{\mathrm{b}}$ & 536 & $17016^{c}$ & 21 & $21380^{\mathrm{a}}$ & 724 \\
\hline kcal & $4588^{\mathrm{b}}$ & 128 & $4067^{c}$ & 5 & $5110^{\mathrm{a}}$ & 173 \\
\hline Waist circumference $(\mathrm{cm})$ & $18 \cdot 3^{\mathrm{b}}$ & 0.3 & $18 \cdot 1^{\mathrm{b}}$ & 0.2 & $19 \cdot 6^{a}$ & 0.4 \\
\hline Mesenteric fat $(\mathrm{g})$ & $5 \cdot 9^{\mathrm{b}}$ & 0.6 & $5 \cdot 1^{\mathrm{b}}$ & 0.3 & $9 \cdot 7^{\mathrm{a}}$ & 0.8 \\
\hline Epididymal fat (g) & $8 \cdot 6^{\mathrm{b}}$ & 0.7 & $9 \cdot 4^{\mathrm{b}}$ & 1.3 & $15 \cdot 4^{\mathrm{a}}$ & 1.2 \\
\hline Retroperitoneal fat $(\mathrm{g})$ & $12 \cdot 4^{\mathrm{b}}$ & 1.3 & $11.4^{\mathrm{b}}$ & $1 \cdot 0$ & $19 \cdot 0^{\mathrm{a}}$ & 1.2 \\
\hline Liver weight (g) & $13 \cdot 5^{\mathrm{b}}$ & 0.8 & $12 \cdot 2^{\mathrm{b}}$ & 0.3 & $16 \cdot 6^{\mathrm{a}}$ & 0.9 \\
\hline
\end{tabular}

a,b,c Mean values with unlike superscript letters were significantly different $(P<0.05$; Tukey-Kramer's post hoc test).

of the HF/HS diet in the present study significantly increased body weight, waist circumference, visceral fat, and liver weight.

\section{Basal and postprandial glycaemic responses during the meal tolerance test}

In the present study, we used the MTT rather than the oral/ intraperitoneal glucose tolerance test to evaluate postprandial glucose tolerance and GLP-1 secretion ${ }^{(32)}$. It should be noted that the control diet was orally administered in all the groups during the MTT after $6 \mathrm{~h}$ deprivation of the respective experimental diets. The MTT was conducted every week to monitor 8-week changes in postprandial responses during the establishment of obesity or glucose intolerance (Table 3) .

Basal glucose levels were significantly higher in the HF/HS group than in the other two groups after day 20 (Fig. 2(a)). Postprandial glucose levels were higher in the HF/HS group than in the other two groups throughout the experimental period due to increased basal glucose levels (Fig. 2(a)). Significant treatment effects were observed on days 6 and 13 for postprandial glycaemic response ( $\Delta$ glucose; Fig. 2(b)). On day 6, significantly higher glycaemic responses compared with the basal level $(0 \mathrm{~min})$ were observed at 15 and $60 \mathrm{~min}$ in the HF/HS group, but only at $15 \mathrm{~min}$ in the control group.
Similarly, the control group showed a significant increment from the basal level only at $15 \mathrm{~min}$, but the $\mathrm{HF} / \mathrm{HS}$ group showed an increment at 15,30 and $60 \mathrm{~min}$ on day 13 . Although a significant effect was not detected by the twoway ANOVA with treatments and days, the one-way ANOVA and post hoc test demonstrated the significant effect of $\mathrm{HF} / \mathrm{HS}$ diet treatment on the AUC of $\Delta$ glucose on day 13 compared with the control group (Fig. 2(c)).

\section{Basal insulin, homeostasis model assessment of insulin resistance and postprandial insulin secretion during the meal tolerance test}

Basal insulin levels in the HF/HS group gradually increased from day 13 to day 50 (Fig. 3(a)), and were significantly higher than those in the other two groups on days 34 and 50. HOMA-IR was also significantly higher in the HF/HS group than in the other two groups (Fig. 3(c)) after day 34. Postprandial insulin levels in the HF/HS group were significantly higher than those in the control group at 15,30 and $60 \mathrm{~min}$ in each MTT (Fig. 3(b)). Furthermore, a significant difference in the AUC of $\Delta$ insulin levels between the HF/HS and control groups was observed on days 34 and 50, and its levels were increased by the chronic intake of the HF/HS diet (Fig. 3(d)).

Table 3. $P$ values for the effects of diet, time and day in the meal tolerance test (MTT) ${ }^{\star}$

\begin{tabular}{lcccrrrr}
\hline & $\mathrm{Tr}$ & $\mathrm{Ti}$ & $\mathrm{D}$ & $\operatorname{Tr} \times \mathrm{Ti}$ & $\operatorname{Tr} \times \mathrm{D}$ & $\mathrm{Ti} \times \mathrm{D}$ & $\operatorname{Tr} \times \mathrm{Ti} \times \mathrm{D}$ \\
\hline Glucose & $<0.05$ & $<0.05$ & $<0.05$ & $<0.05$ & $<0.05$ & $<0.05$ & 0.93 \\
$\Delta$ Glucose & $<0.05$ & $<0.05$ & $<0.05$ & 0.13 & $<0.05$ & $<0.05$ & 0.99 \\
Insulin & $<0.05$ & $<0.05$ & $<0.05$ & $<0.05$ & $<0.05$ & $<0.05$ & $<0.05$ \\
$\Delta$ Insulin & $<0.05$ & $<0.05$ & $<0.05$ & $<0.05$ & $<0.05$ & $<0.05$ & $<0.05$ \\
Total GLP-1 & $<0.05$ & $<0.05$ & $<0.05$ & $<0.05$ & $<0.05$ & 0.28 & 0.55 \\
$\Delta$ Total GLP-1 & $<0.05$ & $<0.05$ & $<0.05$ & $<0.05$ & $<0.05$ & $<0.05$ & 0.16 \\
Acetaminophen & $<0.05$ & $<0.05$ & $<0.05$ & $<0.05$ & $<0.05$ & $<0.05$ & 0.40 \\
\hline
\end{tabular}

Tr, treatment; Ti, time; D, day; GLP-1, glucagon-like peptide-1. * Data obtained from the MTT were analysed by three-way ANOVA. 
Postprandial hormone responses in obesity
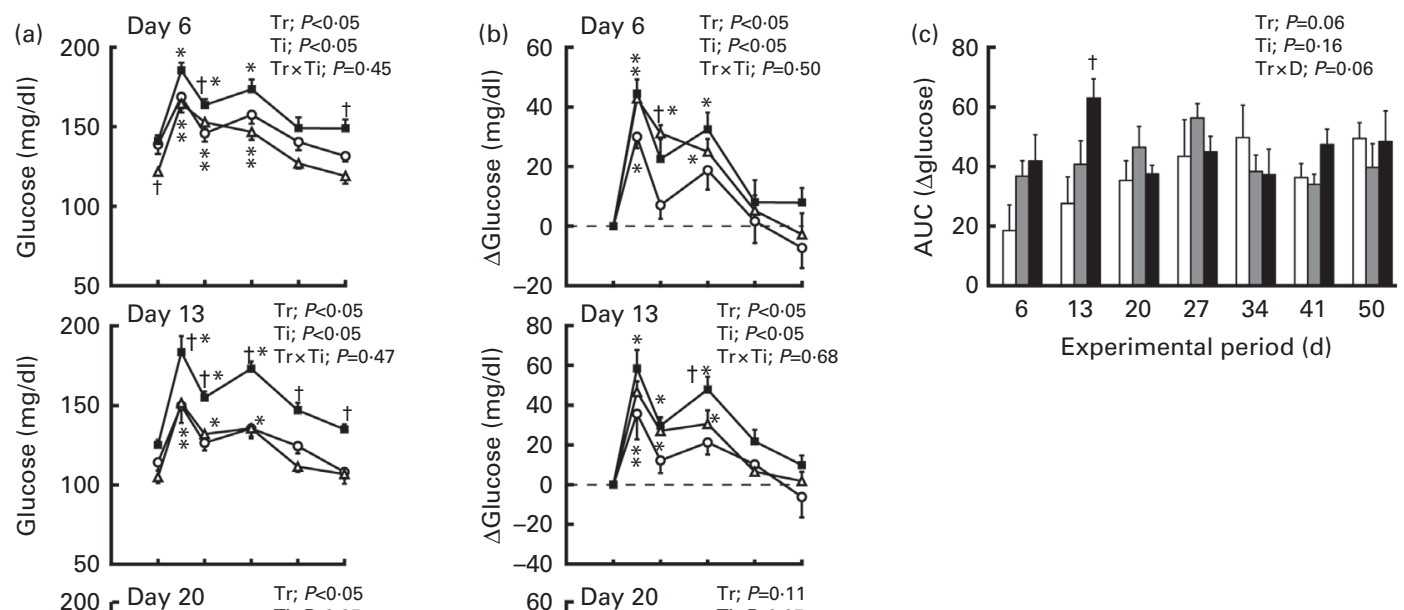

Experimental period $(d)$
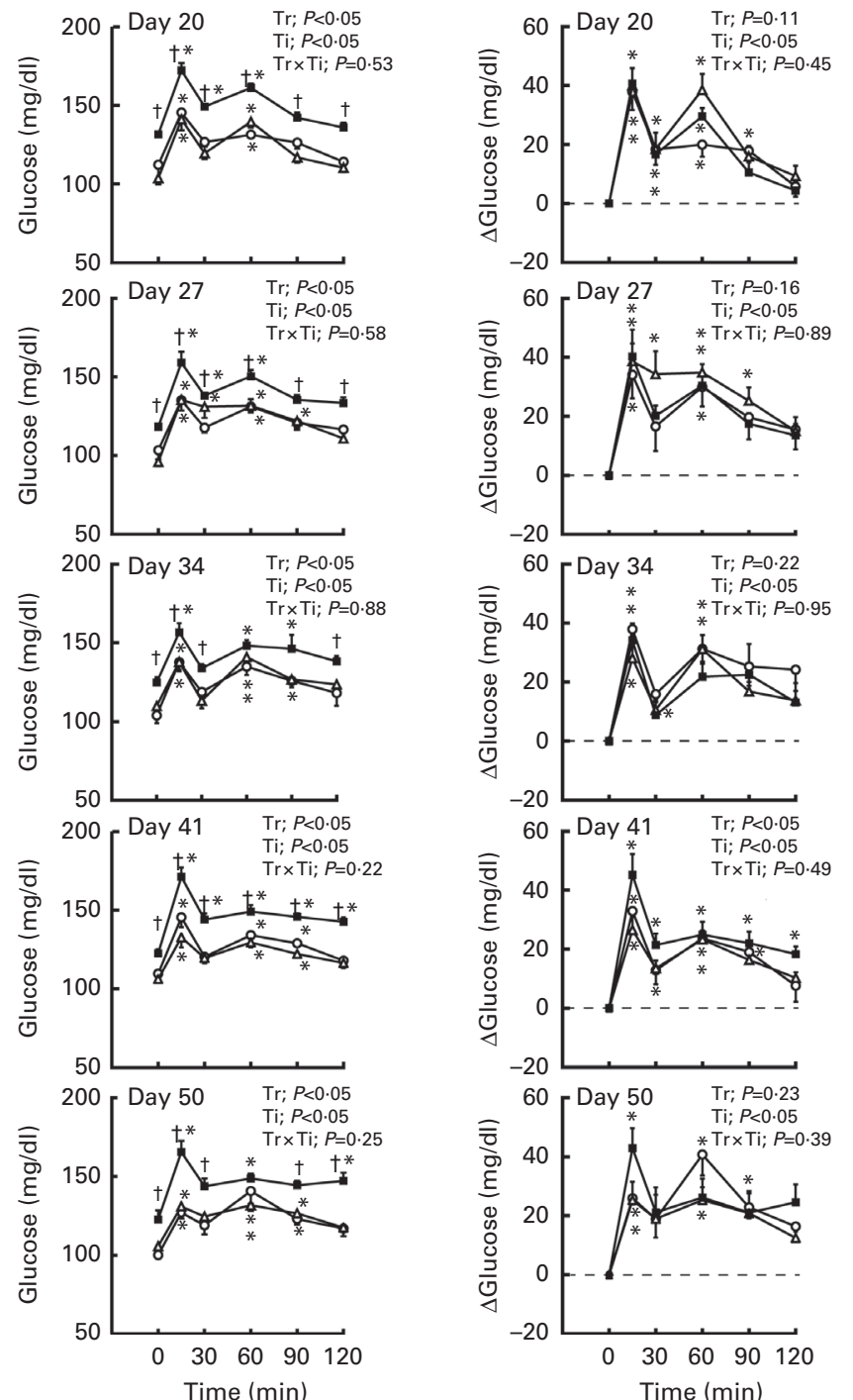

Fig. 2. Postprandial glycaemic responses during the meal tolerance test (MTT). The control diet (American Institute of Nutrition (AIN)-93G) suspended in water was administered orally in rats ( $3 \mathrm{~g} / \mathrm{kg}$ body weight) after $6 \mathrm{~h}$ fasting on days $6,13,20,27,34,41$ and 50 . Rats were fed the control diet ad libitum (O), a restricted amount of the control diet $(\triangle)$ and the high-fat and high-sucrose (HF/HS) diet ad libitum $(\square)$, except on the day of the MTT. Blood samples from the tail vein were collected before $(0 \mathrm{~min})$ and after $(15,30,60,90$ and $120 \mathrm{~min}$ ) the meal load, and plasma glucose levels were measured. (a) Absolute glucose levels and (b) changes from basal levels ( $\Delta$ glucose). (c) AUC of $\Delta$ glucose ( $\square$, control; $\square$, food-restricted; $\square$, HF/HS). Values are means ( $n$ 6-9 rats per group), with their standard errors represented by vertical bars. $P$ values for the effects of treatment $(\mathrm{Tr})$, time (Ti), day (D) and the interaction of treatment and time (TrxTi) or day $(\operatorname{Tr} \times D)$ were calculated by a two-way ANOVA are shown in each subfigure. * Mean value was significantly different from that at baseline $(P<0.05$; TukeyKramer's post hoc test). † Mean value was significantly different from that of the control group $(P<0.05$; Tukey-Kramer's post hoc test). To convert glucose in $\mathrm{mg} / \mathrm{dl}$ to $\mathrm{mmol} / \mathrm{l}$, multiply by 0.0555 . 

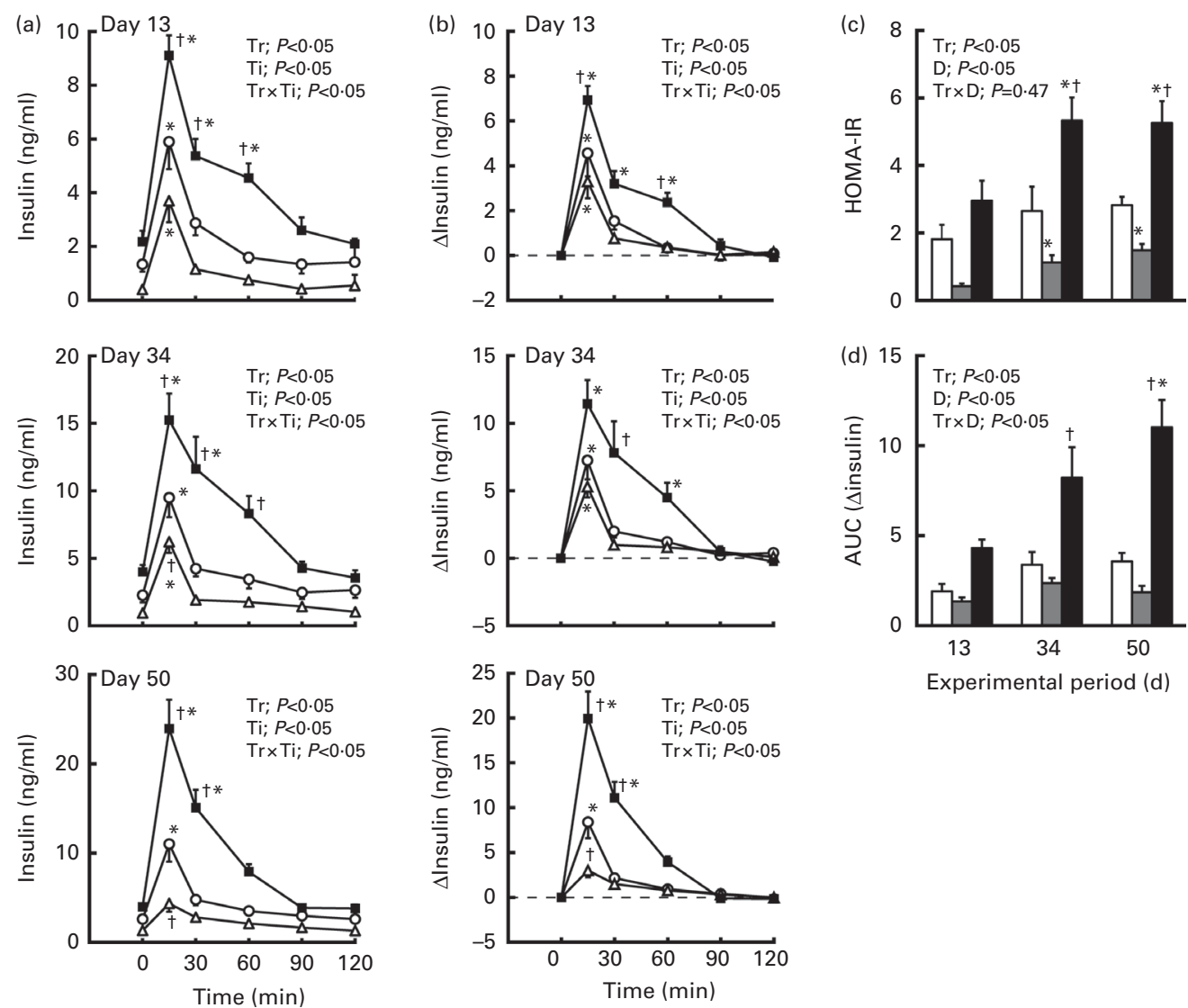

Experimental period $(d)$

Fig. 3. Postprandial insulin secretion during the meal tolerance test (MTT) and fasting homeostasis model assessment of insulin resistance (HOMA-IR). The control diet (American Institute of Nutrition (AIN)-93G) suspended in water was administered orally in rats (3 g/kg body weight) after $6 \mathrm{~h}$ fasting on days 13,34 and 50 . Rats were fed the control diet ad libitum (O), a restricted amount of the control diet $(\Delta)$ and the high-fat and high-sucrose (HF/HS) diet ad libitum ( $\square$ ), except on the day of the MTT. Blood samples from the tail vein were collected before $(0 \mathrm{~min})$ and after $(15,30,60,90$ and $120 \mathrm{~min})$ the meal load, and plasma insulin levels were measured. (a) Absolute insulin levels and (b) changes from basal levels ( $\Delta$ insulin). (c) HOMA-IR was calculated as described in the Materials and methods section. (d) AUC of $\Delta$ insulin ( $\square$, control; $\square$, food-restricted; $\square, H F / H S$ ). Values are means ( $n$ 7-9 rats per group), with their standard errors represented by vertical bars. $P$ values for the effects of treatment $(\mathrm{Tr})$, time $(\mathrm{Ti})$, day $(\mathrm{D})$ and the interaction of treatment and time $(\operatorname{Tr} \times \mathrm{Ti})$ or day $(\operatorname{Tr} \times \mathrm{D})$ were calculated by a two-way ANOVA are shown in each subfigure. * Mean value was significantly different from that at baseline $(P<0.05$; Tukey-Kramer's post hoc test). $\dagger$ Mean value was significantly different from that of the control group $(P<0.05$; Tukey-Kramer's post hoc test).

Basal and postprandial glucagon-like peptide-1 levels during the meal tolerance test

Postprandial GLP-1 secretion in the HF/HS and control groups was significantly higher than its basal levels but not in the food-restricted group on days 13 and 34 (Fig. 4(a) and (b)). GLP-1 levels at $15 \mathrm{~min}$ were significantly higher in the $\mathrm{HF} / \mathrm{HS}$ group than in the control and food-restricted groups on day 50 (Fig. 4(a) and (b)). Furthermore, the AUC of GLP-1 levels in the HF/HS group on day 50 was significantly increased from day 13, which was significantly higher than that in the control group (Fig. 4(c)). The food-restricted group had the lowest basal and postprandial GLP-1 levels among all the groups in each MTT (Fig. 4(a) and (b)).

\section{Postprandial gastric emptying rate during the meal tolerance test}

The rate of gastric emptying affects postprandial glycaemia, and dysregulation of gastric emptying has been reported in obese patients ${ }^{(33)}$ and diet-induced obese rodents ${ }^{(34)}$. The acetaminophen (paracetamol) absorption test is used to assess the gastric emptying rate because acetaminophen is absorbed in the small intestine ${ }^{(25,26)}$. On days 6 and 13, acetaminophen concentrations at 15 and $60 \mathrm{~min}$ after preload of the control diet suspension were significantly lower in the HF/HS group than in the food-restricted group (Fig. 5(a) and (b)). On day 34, acetaminophen concentrations in the $\mathrm{HF} / \mathrm{HS}$ group at 15 and $30 \mathrm{~min}$ were significantly lower than in the control group (Fig. 5(e)). However, on days 41 and 50, significant differences among the treatments were not observed (Fig. 5(f) and (g)).

\section{Portal peptide hormone levels after 8 weeks of high-fat and high-sucrose diet treatment}

On day 56, we collected portal vein samples from overnight fasted rats to evaluate the effect of the HF/HS diet on basal gut hormone levels. Portal GLP-1 concentration was significantly higher in the HF/HS group than in the control 

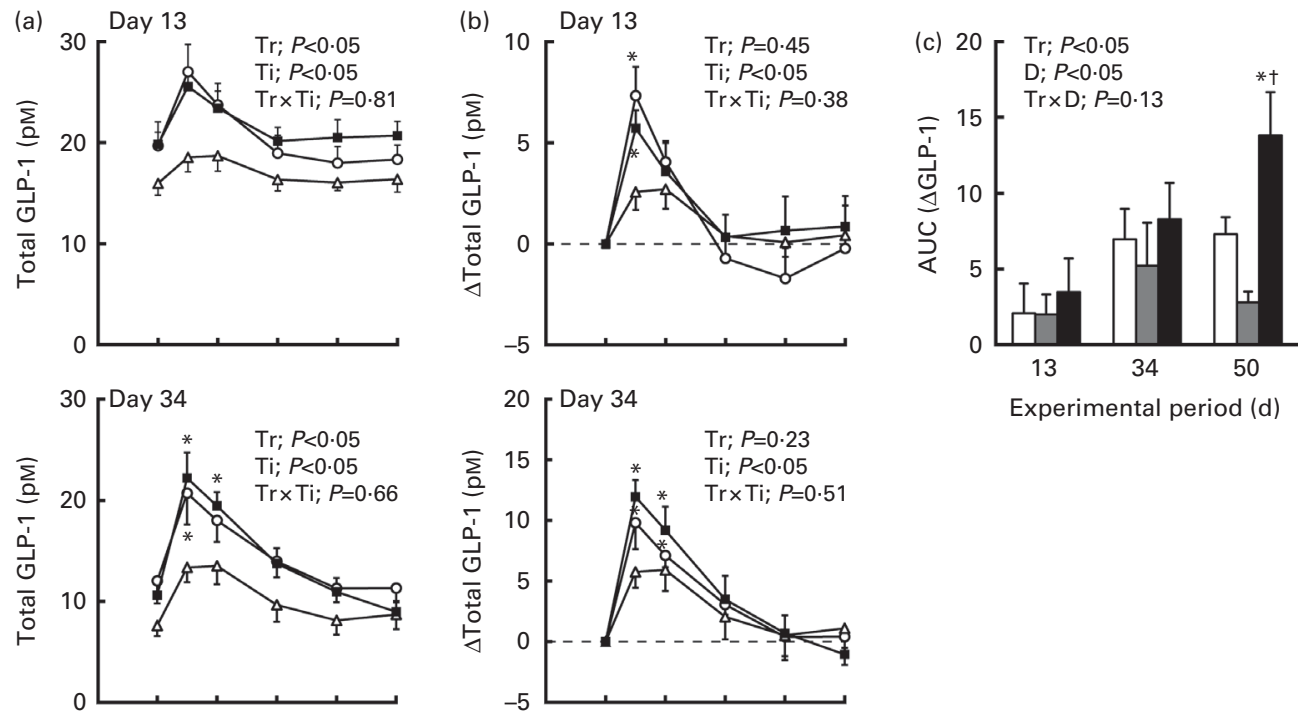

Experimental period $(d)$
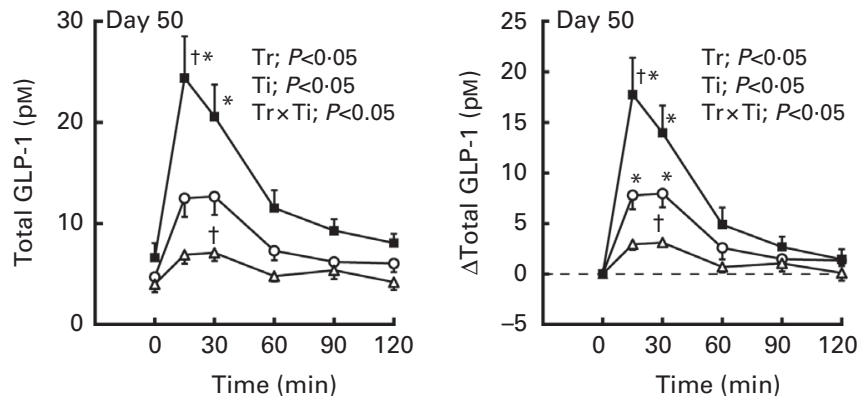

Fig. 4. Postprandial glucagon-like peptide-1 (GLP-1) secretion during the meal tolerance test (MTT). The control diet (American Institute of Nutrition (AIN)-93G) suspended in water was administered orally in rats $(3 \mathrm{~g} / \mathrm{kg}$ body weight) after $6 \mathrm{~h}$ fasting on days 13,34 and 50 . Rats were fed the control diet ad libitum ( 0 ), a restricted amount of the control diet $(\triangle)$ and the high-fat and high-sucrose (HF/HS) diet ad libitum ( $\square$ ), except on the day of the MTT. Blood samples from the tail vein were collected before $(0 \mathrm{~min})$ and after $(15,30,60,90$ and $120 \mathrm{~min})$ the meal load, and plasma total GLP-1 levels were measured. (a) Absolute GLP-1 levels and (b) changes from basal levels ( $\Delta$ GLP-1). (c) AUC of $\Delta$ total GLP-1 ( $\square$, control; $\square$, food-restricted; $\square, \mathrm{HF} / \mathrm{HS}$ ). Values are means ( $n$ 7-9 rats per group), with their standard errors represented by vertical bars. $P$ values for the effects of treatment (Tr), time (Ti), day (D) and the interaction of treatment and time $(\operatorname{Tr} \times \mathrm{Ti})$ or day $(\operatorname{Tr} \times \mathrm{D})$ were calculated by a two-way ANOVA are shown in each subfigure. * Mean value was significantly different from that at baseline $(P<0.05$; Tukey-Kramer's post hoc test). † Mean value was significantly different from that of the control group $(P<0.05$; Tukey-Kramer's post hoc test).

and food-restricted groups (Fig. 6(a)). Although significant difference between portal insulin concentrations in the $\mathrm{HF} / \mathrm{HS}$ and control groups was determined with student's $t$ test $(P=0 \cdot 010)$, there are insignificant changes of insulin levels among all the groups (Fig. 6(b)). Because the CCK EIA kit is able to detect both CCK and gastrin, we measured both CCK and gastrin levels. Portal CCK and gastrin levels did not differ among the three groups (Fig. 6(c) and (d), respectively).

\section{Proglucagon and cholecystokinin mRNA expression in the gastrointestinal tract}

To examine the effect of the HF/HS diet on gut hormone mRNA expression, intestinal mucosa was collected from various regions. Although the GLP-1 level in the portal vein was higher in the HF/HS group (Fig. 6(a)), Gcg mRNA expression did not differ by dietary treatment group for any of the regions (Fig. 7(a)-(d)). Cck mRNA expression was significantly increased in the jejunum depending on energy intake (Fig. 7(f)).

\section{Discussion}

In the present study, we monitored postprandial GLP-1, insulin, glycaemia and gastric emptying in rats during the progression of diet-induced obesity in rats. Daily intake of a HF/HS diet increased postprandial glycaemic and insulin responses to a 'normal diet' (AIN-93G) under the MTT from the early period of the experiment (day 13). After day 20, the HF/HS diet increased fasting glucose and insulin levels compared with the control group, indicating that $\mathrm{HF} / \mathrm{HS}$ feeding induced glucose intolerance accompanied by insulin resistance within 3 weeks in rats. Importantly, postprandial glucose response was not further impaired by the HF/HS diet, and postprandial GLP-1 and insulin responses to the meal in the HF/HS group gradually increased until the end of the experimental period. The present study revealed that the postprandial GLP-1 response to meal ingestion is increased during the progression of glucose intolerance and obesity, which may slow the establishment of diet-induced obesity.

Epidemiological studies have provided evidence that dietary fat intake is closely related to obesity ${ }^{(35,36)}$. Therefore, HF diets have been widely used and recognised to induce diet-related 

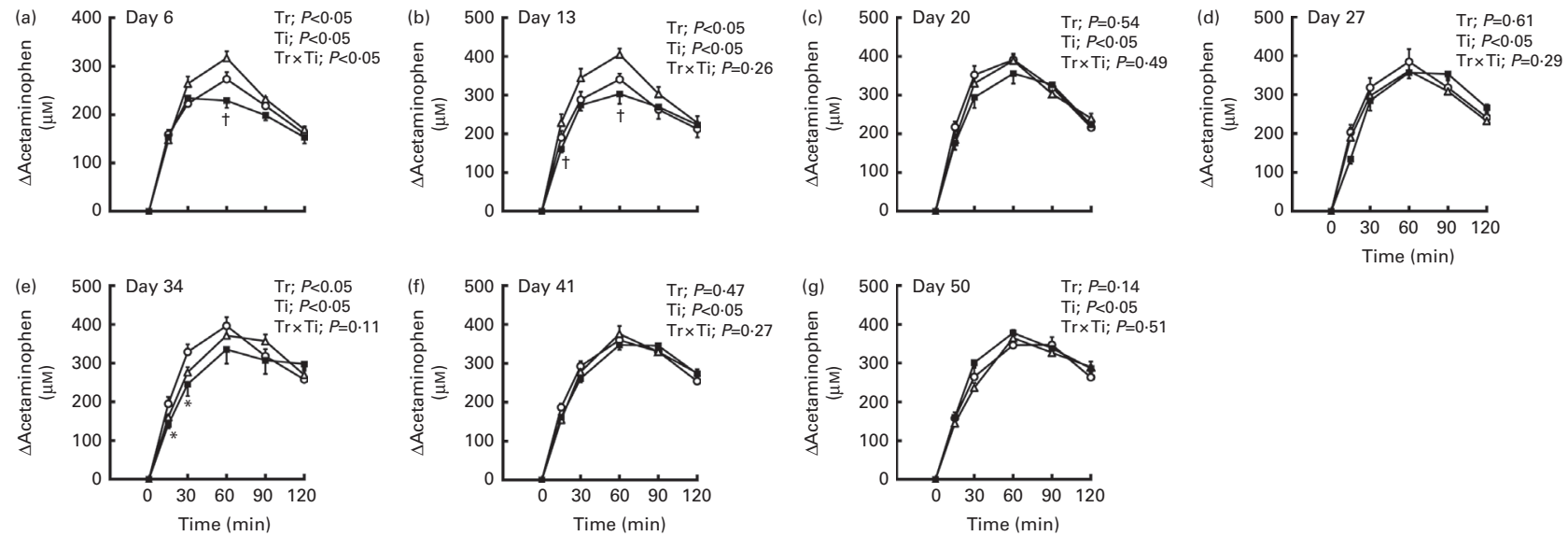

Fig. 5. For Figs 5(d), 5(e) and $5(\mathrm{f})$ - insert $x$ axis label: Time $(\mathrm{min})$ in plasma acetaminophen concentrations during the meal tolerance test (MTT). Acetaminophen $(100 \mathrm{mg} / \mathrm{kg}$ body weight) was orally administered with the control diet (American Institute of Nutrition (AIN)-93G; $3 \mathrm{~g} / \mathrm{kg}$ body weight) in the MTT to assess the gastric emptying rate after $6 \mathrm{~h}$ fasting on days (a) 6, (b) 13, (c) 20, (d) 27, (e) 34, (f) 41 and (g) 50. Rats were fed the control diet ad libitum (o), a restricted amount of the control diet $(\triangle)$ and the high-fat and high-sucrose diet ad libitum $(\square)$, except on the day of the MTT. Changes in plasma acetaminophen levels are shown. Values are means ( $n$ 6-9 rats per group), with their standard errors represented by vertical bars. $P$ values for the effects of treatment $(\mathrm{Tr})$, time (Ti) and the interaction of treatment and time (Tr×Ti) were calculated by a two-way ANOVA are shown in each subfigure. * Mean value was significantly different from that of the control group $(P<0.05$; Tukey-Kramer's post hoc test). † Mean value was significantly different from that of the food-restricted group $(P<0.05 ;$ Tukey-Kramer's post hoc test).

obesity in animal experiments ${ }^{(37,38)}$. Long-term feeding of a sucrose-rich diet has been shown to induce higher glucose levels compared with a HF diet as measured by the oral glucose tolerance test ${ }^{(30)}$. The combination of a HF diet and a HS diet has also been used to induce obesity as a model of the Western diet ${ }^{(39,40)}$. Sucrose consists of glucose and fructose equally, and fructose is known as a highly lipogenic sugar. It has been reported that excessive consumption of commercial beverages containing glucose and fructose (high-fructose maize syrup: 50\% glucose and 50\% fructose) has been linked to the development of the metabolic syndrome $^{(41)}$

As shown in Figs. 2 and 3, weekly monitoring of postprandial glycaemia and insulin responses revealed that glucose intolerance was induced in rats just after 2 weeks on the HF/HS diet. Significant differences in body weight between the control and HF/HS groups were observed from day 30 (Fig. 1), indicating that impairment of glucose homeostasis occurs in advance of body-weight increase. Generally, dietinduced obesity animal models are studied after feeding with high-energy diets for 8 weeks or longer. However, the present result suggests that postprandial glucose intolerance is immediately caused by a daily intake of a high-energy diet rich in fat and sucrose as is the case in the intravenous glucose tolerance test ${ }^{(42)}$. The food-restricted group was fed the control diet with the same amount (in $\mathrm{g}$ ) as that consumed by the HF/HS group (Table 2), so that both groups consumed the same amounts of protein, vitamins and minerals, and finally both groups had lower protein/vitamin/mineral intake compared with the control group. However, the foodrestricted group did not show the similar phenotype to the $\mathrm{HF} / \mathrm{HS}$ group on postprandial response, suggesting that excessive energy intake, rather than the reduced intake of protein, vitamins and minerals, has a large impact on the impairment of postprandial glycaemia. The food-restricted group showed almost similar postprandial glycaemia overall, but relatively smaller responses in insulin and GLP-1 secretion compared with the control group (Figs. 2-4), suggesting that restriction $(90 \%)$ of food consumption is beneficial for the improvement of glucose tolerance. However, it is possible that these results were observed due to the lower body weight
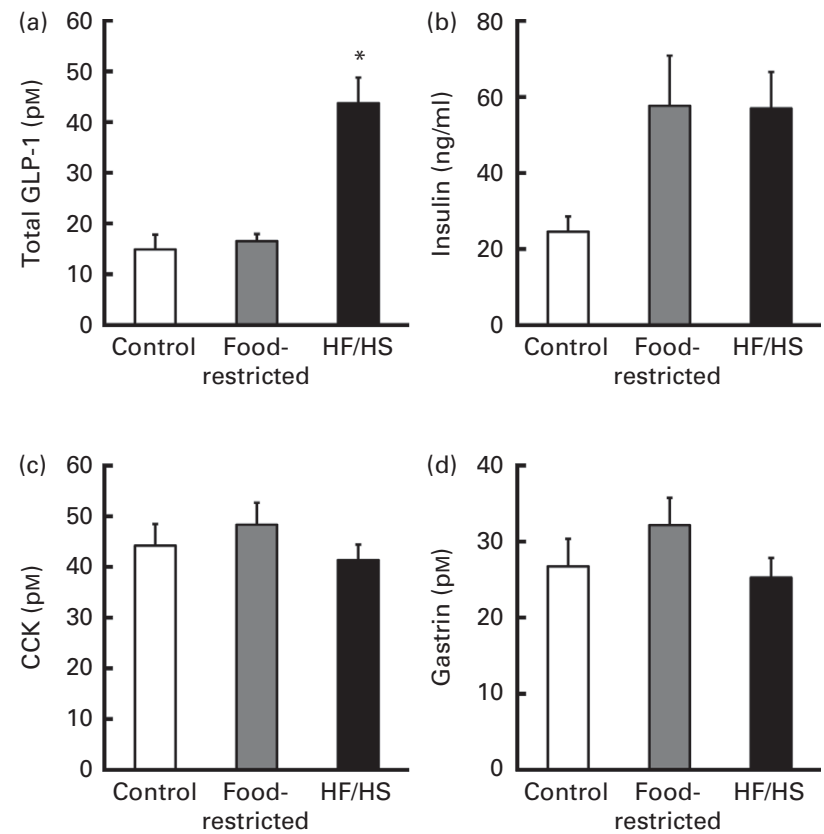

Fig. 6. Fasting peptide hormone levels in the portal vein of rats fed the respective test diets for 8 weeks. Portal blood was collected from the rats after overnight fasting on day 56. The levels of (a) total glucagon-like peptide-1 (GLP-1), (b) insulin, (c) cholecystokinin (CCK) and (d) gastrin were measured by respective EIA kits. Values are means ( $n$ 8-9 rats per group), with their standard errors represented by vertical bars. * Mean value was significantly different from that of the control group $(P<0.05$; Tukey-Kramer's post hoc test). HF/HS diet, high-fat and high-sucrose diet. 

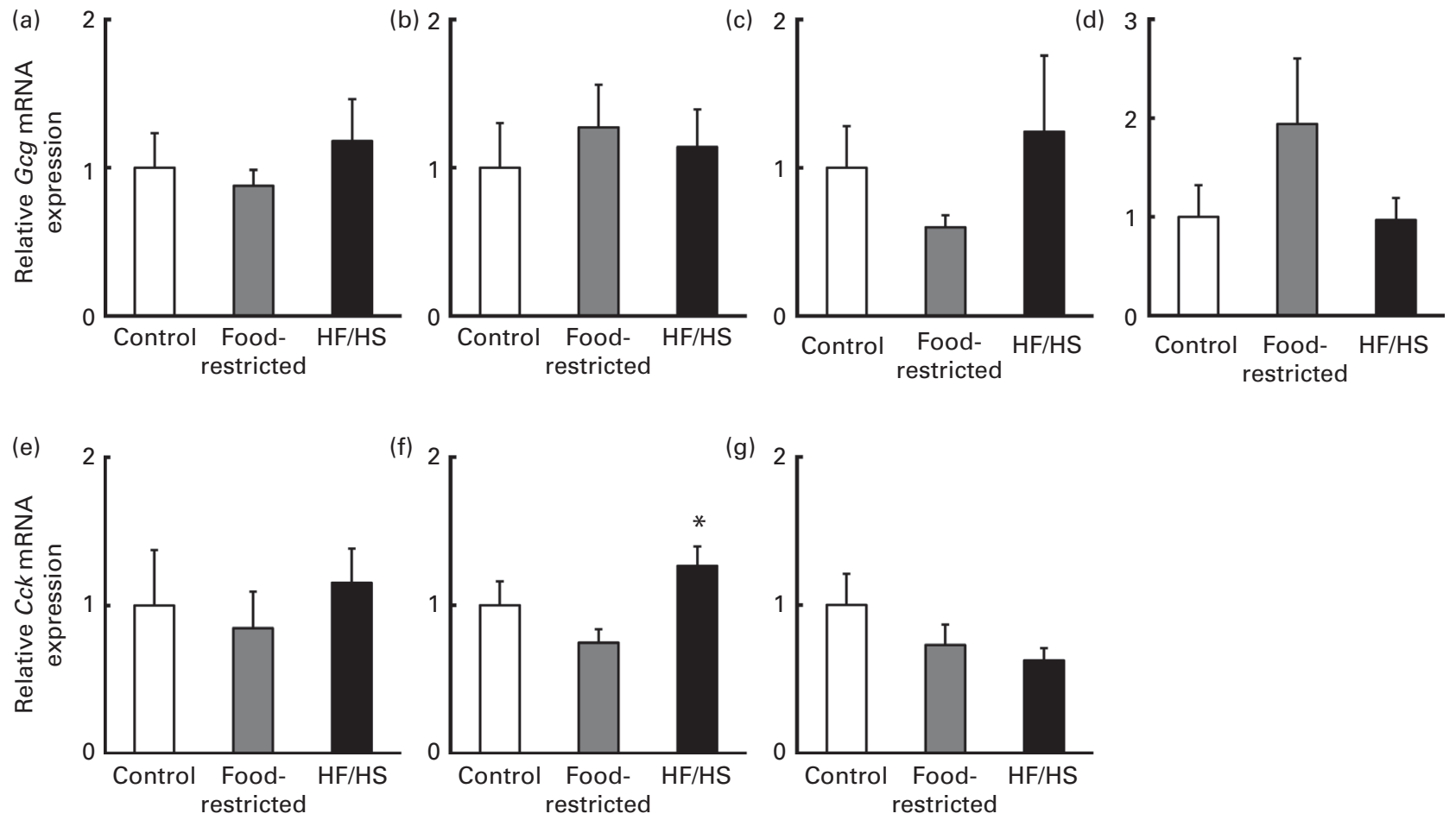

Fig. 7. Proglucagon ( $G c g)$ and cholecystokinin (Cck) mRNA expression in the intestinal mucosa of rats fed the respective test diets for 8 weeks. Mucosa was collected from the (a, f) jejunum, (b, g) ileum, (c) caecum, (d) colon and (e) duodenum of rats after overnight fasting on day 56. The mRNA expression levels of $(\mathrm{a}-\mathrm{d}) \mathrm{Gcg}$ and $(\mathrm{e}-\mathrm{g})$ Cck were determined by real-time quantitative PCR. Data are presented as the relative expression level to that of the control group normalised to glyceraldehyde 3-phosphate dehydrogenase (Gapdh) mRNA expression. Values are means ( $n$ 8-9 rats per group), with their standard errors represented by vertical bars. * Mean value was significantly different from that of the food-restricted group $(P<0.05$; Tukey-Kramer's post hoc test). HF/HS diet, high-fat and high-sucrose diet.

and lower energy load in the food-restricted group than in the control group. Another limitation is that the food-restricted group had a longer fasting period because they finished the diet every day before they were given a fresh diet.

The effects of each macronutrient (carbohydrate, fat and protein) on gut hormone secretion have been reported, and the ratio of fat:protein is closely related to GLP-1 secretion in healthy subjects ${ }^{(43,44)}$. The intake of a mixed meal has a potent effect on GLP-1 secretion compared with solo administration of each macronutrient ${ }^{(31)}$. It has been previously reported that the MTT represents a better indication of normal postprandial glucose and insulin responses compared with the oral glucose tolerance test in a population-based cohort $^{(45)}$. In the present study, the MTT was conducted (rather than the widely used oral glucose tolerance test) to evaluate 'postprandial' glycaemic and gastrointestinal responses under a more physiological condition reflecting dietary exposure in normal life. As equivalent dietary components are used to compare the effect of the diet on obesity, as shown in the clinical study ${ }^{(46,47)}$, all rats received a normal diet rather than the respective test diets in the MTT. For the $\mathrm{HF} / \mathrm{HS}$ group, the control diet administered was different from the usual diet (HF/HS diet). However, all rats received the control diet during the acclimatisation period before feeding the respective test diets; therefore, having the control diet in the MTT was not for the first time even for the HF/HS group. In addition, all rats were subjected to oral administration of the water-suspended diet in the MTT. Although the composition of the diet was unchanged for the control group, the form and way of ingestion were changed from the usual 'meal' for all the groups. Therefore, we assume that the impact of changing diet composition from daily consuming the HF/HS diet on postprandial responses in the HF/HS group was smaller than the chronic effect of the HF/HS diet. Because daily postprandial responses would be an important factor that would affect metabolic status, it is interesting to know the daily glycaemic, insulin and GLP-1 responses in each group after having the respective test diets. However, if the MTT had been performed in such a way, interpretations of the observed result would be complicated with respect to nutrient sensing because both chronic and acute effects of the respective diet compositions could affect postprandial responses. It would be interesting to examine the postprandial response to the HF/HS diet or a single nutrient load in the control and HF/HS groups in the future.

Previous reports have demonstrated that the peak of GLP-1 secretion after oral glucose administration was decreased in diet-induced obesity ${ }^{(16,17)}$. In contrast, it has been reported that GLP-1 secretion in response to oral fatty acid administration was unchanged between diet-induced obesity rats and diet-resistant rats ${ }^{(18)}$. Interestingly, the present study showed that postprandial GLP-1 response (to a normal diet) was gradually increased, but not decreased, by chronic intake of the HF/HS diet compared with the control diet, and a significant difference was observed after 7 weeks (Fig. 4). The result suggests that chronic intake of the HF/HS 
diet altered the nutrient-sensing function of the gastrointestinal tract to be more sensitive to the mixed meal. Possibly, the different postprandial responses arose from different amounts of energy load ${ }^{(24)}$, because the meal was given depending on the body weight of individual rats $(3 \mathrm{~g} / \mathrm{kg})$ in the MTT of the present study. Indeed, the body weight of the HF/HS group was about $50 \mathrm{~g}(12 \%)$ higher than that of the control group, and energy load in the HF/HS group was $12 \%$ higher than that in the control group. Although a similar difference in body weight (10\%) was already observed on day 34, postprandial GLP-1 response was 2-fold higher in the $\mathrm{HF} / \mathrm{HS}$ group than in the control group (Fig. 4(b) and (c)). Furthermore, data (see online supplementary Fig. S1) comparing selected rats having higher body weight in the control group and those having lower body weight in the $\mathrm{HF} / \mathrm{HS}$ group demonstrated that GLP-1 and insulin responses are apparently higher in the HF/HS group than in the control group, although there was no significant difference in body weight between the two groups.

The present results also demonstrated that fasting GLP-1 levels in the portal vein were increased in the HF/HS group (Fig. 6), but Gcg mRNA expression did not differ by dietary treatments in any of the intestinal regions (Fig. 7), which implies that GLP-1 secretion, but not mucosal GLP-1 production, was changed by the $\mathrm{HF} / \mathrm{HS}$ diet. Despite the change $(\Delta)$ in postprandial plasma glucose concentrations was not increased from day 20 to day 50 (Fig. 2(b)), enhancement of postprandial and fasting GLP-1 levels with increased insulin secretion was observed (Figs. 3, 4 and 6). Although gut hormones, such as GLP-1, are immediately secreted in response to meal ingestion, adaptive changes to a chronic high-energy diet develop over time in peripheral insulintargeting tissues such as adipose tissue, and liver and skeletal muscles. The physiological relevance of increased GLP-1 and nutrient sensitivity needs to be further studied in the future, which may contribute to the prevention of excessive plasma glucose elevation and slow the establishment of glucose intolerance and obesity with the enhancement of insulin secretion.

Changes in acetaminophen concentration were smaller in the HF/HS group compared with the control group during the MTT on day 34 (Fig. 5(e)), suggesting delayed gastric emptying in the HF/HS group. Such an effect might prevent excessive loading of nutrients in the small intestine in the HF/HS group. Several reports have demonstrated that the dosage of luminal nutrients, including fat and protein, is an important factor for GLP-1 secretion ${ }^{(48,49)}$. On day 34 , postprandial GLP-1 levels in the HF/HS group were similar to those in the control group, although gastric emptying was delayed in the HF/HS group (Figs. 4(b) and 5(e)). In contrast, increased postprandial GLP-1 secretion and unchanged postprandial gastric emptying were observed on day 50 (Figs. 4(b) and $5(\mathrm{~g}))$. GLP-1 secretion depends on luminal nutrients that are emptied from the stomach, but gastric emptying is regulated by various factors, such as CCK, serotonin and GLP-1. Although significant treatment effects were detected on days 6, 13 and 34 by the two-way ANOVA, it is unclear how such changes in the gastric emptying rate appeared and contribute to postprandial hormone and glycaemic responses in the present study.

In summary, feeding rats with a HF/HS diet rapidly impaired postprandial glycaemic responses (i.e. within 2 weeks) in advance of increased weight gain. Postprandial GLP-1 secretion during the MTT was increased by HF/HS diet treatment after 7 weeks. Food restriction demonstrates that habitual excessive energy (fat and sucrose) intake is the main factor that contributes to changes in postprandial GLP-1 secretion. Although mRNA expression levels of gut hormones were unchanged, fasting GLP-1 and insulin levels in portal blood were increased by the $\mathrm{HF} / \mathrm{HS}$ diet after 8 weeks. The present study revealed that chronic ingestion of a high-energy diet elevates postprandial GLP-1 and insulin responses to meal ingestion in rats. The boosted postprandial GLP-1 secretion by chronic high-energy diet treatment suggests enhanced sensitivity to luminal nutrients in the gut, which may slow the establishment of glucose intolerance and obesity.

\section{Supplementary material}

To view supplementary material for this article, please visit http://dx.doi.org/10.1017/S0007114515000550

\section{Acknowledgements}

The present study was supported by JSPS KAKENHI (grant no. 11J07124).

The authors' contributions are as follows: S. N., T. H. and H. H. designed the research; S. N. conducted the research and analysed the data; S. N. and T. H. wrote the paper; T. H. had primary responsibility for the final content. All authors read and approved the final manuscript.

The authors declare that they have no conflicts of interest.

\section{References}

1. De Pergola G \& Silvestris F (2013) Obesity as a major risk factor for cancer. J Obes 2013, 291546.

2. Hryhorczuk C, Sharma S \& Fulton SE (2013) Metabolic disturbances connecting obesity and depression. Front Neurosci 7, 177.

3. Golay A \& Ybarra J (2005) Link between obesity and type 2 diabetes. Best Pract Res Clin Endocrinol Metab 19, 649-663.

4. Campbell JE \& Drucker DJ (2013) Pharmacology, physiology, and mechanisms of incretin hormone action. Cell Metab 17, 819-837.

5. Troke RC, Tan TM \& Bloom SR (2014) The future role of gut hormones in the treatment of obesity. Ther Adv Chronic Dis 5, 4-14

6. Irwin N \& Flatt PR (2013) Enteroendocrine hormone mimetics for the treatment of obesity and diabetes. Curr Opin Pharmacol 13, 989-995.

7. Meier JJ, Gallwitz B, Salmen S, et al. (2003) Normalization of glucose concentrations and deceleration of gastric emptying after solid meals during intravenous glucagon-like peptide 1 in patients with type 2 diabetes. J Clin Endocrinol Metab 88, $2719-2725$. 
8. Holst JJ (2007) The physiology of glucagon-like peptide 1. Physiol Rev 87, 1409-1439.

9. Rocca AS, LaGreca J, Kalitsky J, et al. (2001) Monounsaturated fatty acid diets improve glycemic tolerance through increased secretion of glucagon-like peptide-1. Endocrinology 142, 1148-1155.

10. Higuchi N, Hira T, Yamada N, et al. (2013) Oral administration of corn zein hydrolysate stimulates GLP-1 and GIP secretion and improves glucose tolerance in male normal rats and Goto-Kakizaki rats. Endocrinology 154, 3089-3098

11. Rathmann W, Kostev K, Gruenberger JB, et al. (2013) Treatment persistence, hypoglycaemia and clinical outcomes in type 2 diabetes patients with dipeptidyl peptidase- 4 inhibitors and sulphonylureas: a primary care database analysis. Diabetes Obes Metab 15, 55-61.

12. Wysham C, Grimm M \& Chen S (2013) Once weekly exenatide: efficacy, tolerability and place in therapy. Diabetes Obes Metab 15, 871-881.

13. Nauck MA, Vardarli I, Deacon CF, et al. (2011) Secretion of glucagon-like peptide-1 (GLP-1) in type 2 diabetes: what is up, what is down? Diabetologia 54, 10-18.

14. Smushkin G, Sathananthan A, Man CD, et al. (2012) Defects in GLP-1 response to an oral challenge do not play a significant role in the pathogenesis of prediabetes. $J$ Clin Endocrinol Metab 97, 589-598.

15. Alssema M, Rijkelijkhuizen JM, Holst JJ, et al. (2013) Preserved GLP-1 and exaggerated GIP secretion in type 2 diabetes and relationships with triglycerides and ALT. Eur J Endocrinol 169, 421-430.

16. Gniuli D, Calcagno A, Dalla Libera L, et al. (2010) High-fat feeding stimulates endocrine, glucose-dependent insulinotropic polypeptide (GIP)-expressing cell hyperplasia in the duodenum of Wistar rats. Diabetologia 53, 2233-2240.

17. Anini Y \& Brubaker PL (2003) Role of leptin in the regulation of glucagon-like peptide-1 secretion. Diabetes 52, 252-259.

18. Paulsen SJ, Larsen LK, Hansen G, et al. (2014) Expression of the fatty acid receptor GPR120 in the gut of diet-inducedobese rats and its role in GLP-1 secretion. PLOS ONE 9, e88227.

19. Liuzzi JP, Blanchard RK \& Cousins RJ (2001) Differential regulation of zinc transporter 1,2 , and 4 mRNA expression by dietary zinc in rats. $J$ Nutr 131, 46-52.

20. Zineb R, Zhor B, Odile W, et al. (1998) Distinct, tissuespecific regulation of vitamin $\mathrm{D}$ receptor in the intestine, kidney, and skin by dietary calcium and vitamin D. Endocrinology 139, 1844-1852.

21. Chen H, Pan Y, Wong EA, et al. (2005) Dietary protein level and stage of development affect expression of an intestinal peptide transporter (cPepT1) in chickens. J Nutr $\mathbf{1 3 5}$, 193-198.

22. Andrikopoulos S, Blair AR, Deluca N, et al. (2008) Evaluating the glucose tolerance test in mice. Am J Physiol Endocrinol Metab 295, E1323-E1332.

23. Lu M, Patsouris D, Li P, et al. (2010) A new antidiabetic compound attenuates inflammation and insulin resistance in Zucker diabetic fatty rats. Am J Physiol Endocrinol Metab 298, E1036-E1048.

24. Ayala JE, Samuel VT, Morton GJ, et al. (2010) Standard operating procedures for describing and performing metabolic tests of glucose homeostasis in mice. Dis Model Mech 3, 525-534.

25. Heading RC, Nimmo J, Prescott LF, et al. (1973) The dependence of paracetamol absorption on the rate of gastric emptying. Br J Pharmacol 47, 415-421.
26. Maida A, Lovshin JA, Baggio LL, et al. (2008) The glucagonlike peptide-1 receptor agonist oxyntomodulin enhances $\beta$-cell function but does not inhibit gastric emptying in mice. Endocrinology 149, 5670-5678.

27. Soliman HM, Wagih HM, Algaidi SA, et al. (2013) Histological evaluation of the role of atypical antipsychotic drugs in inducing non-alcoholic fatty liver disease in adult male albino rats (light and electron microscopic study). Folia Biol (Praha) 59, 173-180.

28. Schroeder M, Zagoory-Sharon O, Shbiro L, et al. (2009) Development of obesity in the Otsuka Long-Evans Tokushima fatty rat. Am J Physiol Regul Integr Comp Physiol 297, R1749-R1760.

29. Rehfeld JF (1998) How to measure cholecystokinin in tissue, plasma and cerebrospinal fluid. Regul Pept 78, 31-39.

30. Sumiyoshi M, Sakanaka M \& Kimura Y (2006) Chronic intake of high-fat and high-sucrose diets differentially affects glucose intolerance in mice. J Nutr 136, 582-587.

31. Buettner R, Parhofer KG, Woenckhaus M, et al. (2006) Defining high-fat-diet rat models: metabolic and molecular effects of different fat types. J Mol Endocrinol 36, 485-501.

32. Ahlkvist L, Vikman J, Pacini G, et al. (2012) Synergism by individual macronutrients explains the marked early GLP-1 and islet hormone responses to mixed meal challenge in mice. Regul Pept 178, 29-35.

33. Jackson SJ, Leahy FE, McGowan AA, et al. (2004) Delayed gastric emptying in the obese: an assessment using the non-invasive ${ }^{13} \mathrm{C}$-octanoic acid breath test. Diabetes Obes Metab 6, 264-270.

34. Li J, Ma W \& Wang S (2011) Slower gastric emptying in highfat diet induced obese rats is associated with attenuated plasma ghrelin and elevated plasma leptin and cholecystokinin concentrations. Regul Pept 171, 53-57.

35. Bray GA \& Popkin BM (1998) Dietary fat intake does affect obesity! Am J Clin Nutr 68, 1157-1173.

36. Hill JO \& Peters JC (1998) Environmental contributions to the obesity epidemic. Science 280, 1371-1374.

37. Buettner R, Schölmerich J \& Bollheimer LC (2007) High-fat diets: modeling the metabolic disorders of human obesity in rodents. Obesity (Silver Spring) 15, 798-808.

38. Hariri N \& Thibault L (2010) High-fat diet-induced obesity in animal models. Nutr Res Rev 23, 270-299.

39. Aoun M, Michel F, Fouret G, et al. (2011) A grape polyphenol extract modulates muscle membrane fatty acid composition and lipid metabolism in high-fat-high-sucrose diet-fed rats. Br J Nutr 106, 491-501.

40. Sato A, Kawano H, Notsu T, et al. (2010) Antiobesity effect of eicosapentaenoic acid in high-fat/high-sucrose diet-induced obesity: importance of hepatic lipogenesis. Diabetes 59, 2495-2504.

41. Dekker MJ, Su Q, Baker C, et al. (2010) Fructose: a highly lipogenic nutrient implicated in insulin resistance, hepatic steatosis, and the metabolic syndrome. Am J Physiol Endocrinol Metab 299, E685-E694.

42. la Fleur SE, Luijendijk MC, van Rozen AJ, et al. (2011) A freechoice high-fat high-sugar diet induces glucose intolerance and insulin unresponsiveness to a glucose load not explained by obesity. Int J Obes (Lond) 35, 595-604.

43. Carrel G, Egli L, Tran C, et al. (2011) Contributions of fat and protein to the incretin effect of a mixed meal. Am J Clin Nutr 94, 997-1003.

44. Wikarek T, Chudek J, Owczarek A, et al. (2014) Effect of dietary macronutrients on postprandial incretin hormone release and satiety in obese and normal-weight women. Br J Nutr 111, 236-246. 
45. Rijkelijkhuizen JM, Girman CJ, Mari A, et al. (2009) Classical and model-based estimates of $\beta$-cell function during a mixed meal vs. an OGTT in a population-based cohort. Diabetes Res Clin Pract 83, 280-288.

46. Bowen J, Noakes M \& Clifton PM (2005) Effect of calcium and dairy foods in high protein, energy-restricted diets on weight loss and metabolic parameters in overweight adults. Int J Obes (Lond) 29, 957-965.

47. Parnell JA \& Reimer RA (2009) Weight loss during oligofructose supplementation is associated with decreased ghrelin and increased peptide $\mathrm{YY}$ in overweight and obese adults. Am J Clin Nutr 89, 1751-1759.

48. Hira T, Mochida T, Miyashita K, et al. (2009) GLP-1 secretion is enhanced directly in the ileum but indirectly in the duodenum by a newly identified potent stimulator, zein hydrolysate, in rats. Am J Physiol Gastrointest Liver Physiol 297, G663-G671.

49. Yoder SM, Yang Q, Kindel TL, et al. (2009) Stimulation of incretin secretion by dietary lipid: is it dose dependent? Am J Physiol Gastrointest Liver Physiol 297, G299-G305. 